\title{
Endodontic Enigma: A case report series of mandibular premolars with two root canals
}

\author{
Shalini Singh 1,", Nitin Mirdha², Mariam Belim ${ }^{3}$, Roshni Arora ${ }^{4}$, Rahul VC Tiwari ${ }^{5}$ \\ ${ }^{1,3,4}$ Postraduate Student, ${ }^{2}$ Associate Professor, Dept. of Conservative Dentistry and Endodontics, Vyas Dental College and \\ Hospital, Jodhpur, Rajasthan, ${ }^{5}$ FOGS, OMFS, Jubilee Mission Medical College, Hospital \&Research Institute, Thrissur, Kerala, \\ India
}

*Corresponding Author:

Email: drshalinisingh27@gmail.com

\begin{abstract}
Endodontic treatment success depends on biomechanical preparation and 3-D obturation. Mandibular premolars have been reported with aberrant anatomy. The endodontic treatment of mandibular premolars may have major failure due to unrecognized or untreated multiple canals when they are present. Hence a thorough knowledge of the root canal morphology, careful radiographic interpretation and access cavity modifications are essentials for enhancing endodontic procedures.
\end{abstract}

Keywords: Mandibular premolars, multiple canals, root canal treatment.

\section{Introduction}

Mandibular premolars show aberrant root canal anatomy and morphology. If all the root canals are not located and properly treated, cases could result in flareups and/or failures ${ }^{1}$. It was reported that $24.2 \%$ of mandibular first premolars have two or more root canals, and multiple foramina at the apex is $20 \%{ }^{2}$ Seelig $^{3}$ reported that $97.5 \%$ mandibular second premolar had only one root canal at the apex and only $2.5 \%$ had two canals, whereas three root canals are rare. It is reported that $5.3 \%$ of mandibular second premolar had two canals with two foramen and $44 \%$ had two canals with one foramen, and $0.4-5 \%$ had three canals with three foramen. ${ }^{4}$

\section{Case Report 1}

A 30 year old patient reported to Department of Conservative dentistry and Endodontics with the chief complaint of pain in relation to right back region of mandible. Proper clinical examination was done and case history was taken. Clinical examination revealed deep proximal caries in mandibular right second premolar, and on thorough evaluation of diagnostic radiograph two canals were observed (Fig. 1A). A diagnosis of irreversible pulpitis was established.

The tooth was anaesthetized followed by rubber dam (Hygenic) isolation. Access cavity was prepared using a round diamond bur in a high speed airotar hand piece. A sharp DG16 explorer was used to locate the canal orifices, and the access was modified accordingly. Pulp extirpation was done, after checking the patency of the two canals, with\# 10K file (Dentsply-Maillefer), the working length was assessed with the help of electronic apex locator (Propex II), and further it was confirmed with the help of radiograph (Fig. 1B). Biomechanical preparation was performed using ProTaper File system (Dentsply-Maillefer) with crowndown technique. During the preparation 5\% sodium hypochlorite solution and $17 \%$ EDTA was used as irrigant alternatively after every instrument change. Apical Preparation was done till F2 size for both the canals, after completion of chemo-mechanical preparation closed dressing was given and patient was reappointed after 3 days for obturation. In follow-up appointment as the tooth was completely asymptomatic master cone radiograph was taken (Fig. 1C). The canals were dried using paper point. Obturation was done using corresponding ProTaper F2 cones; sealapex (Kerr, SybronEndo) was used as a sealer. Radiograph after obturation is taken (Fig. 1D). Post-obturation restoration was done using composite (Filtek Z250, $3 \mathrm{M})$ and post-operative radiograph was taken (Fig. 1E).

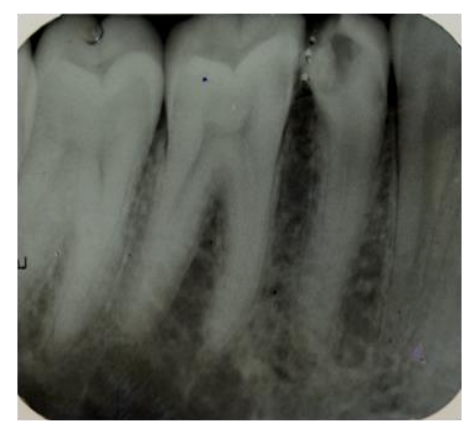

Fig. 1A: Pre-operative diagnostic radiograph

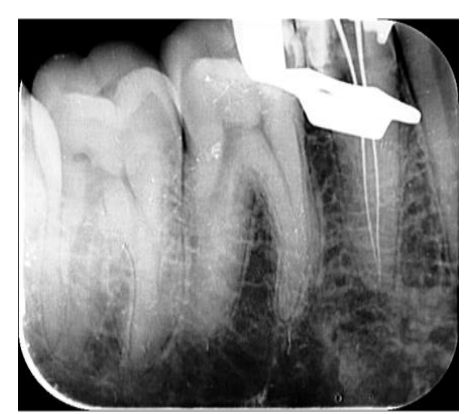

Fig. 1B: Working length confirmation radiograph 


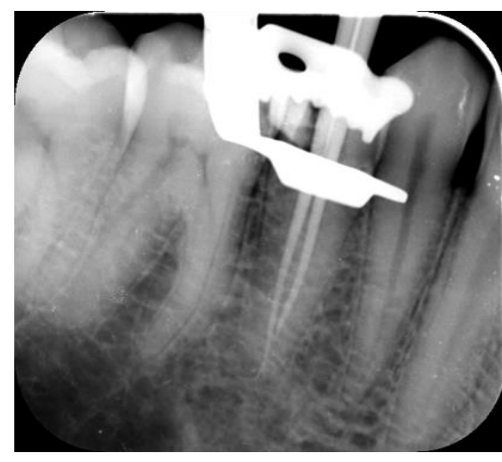

Fig. 1C: Master cone radiograph

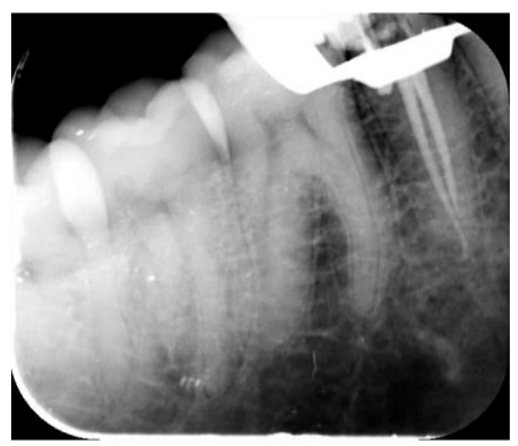

Fig. 1D: Radiograph after obturation

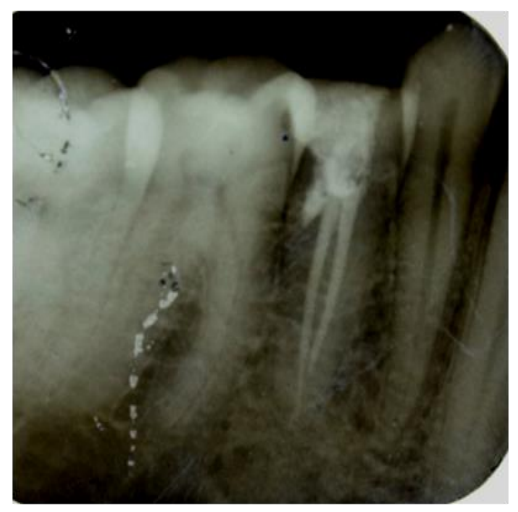

Fig. 1E: Radiograph with post obturation restoration

\section{Case Report 2}

A 27 year old patient who had pain in right back region of mandible reported to Department of Conservative dentistry and Endodontics. Case history was taken and a detailed clinical examination was done. Intraoral examination revealed deep proximal caries in relation to right lower first premolar. Vitality test was done and diagnostic radiograph was taken (Fig. 2A), which was suggestive of irreversible pulpitis, and on meticulous evaluation two canals were seen.

The tooth was anesthetized and rubber dam (Hygenic) isolation was done. Standard root canal procedure was performed, after deroofing two distinct orifices were located using DG16. Canal patency was obtained by size $10 \mathrm{k}$ (malleifer) files and working length was determined using electronic apex locator (Propex II) radiograph taken with mesial angulation for working length confirmation (Fig. 2B). After establishing glide path with size $10 \mathrm{~K}$ and $15 \mathrm{~K}$ (malleifer) files, both the canals were shaped using ProTaper File system (Dentsply-Maillefer, Ballaigues, Switzerland) with a crown down technique. 5\% sodium hypochlorite solution and $17 \%$ EDTA was used as irrigant alternatively after every instrument change, recapitulation was done using smaller size file. Apical preparation was done till F2 ProTaper. After biomechanical preparation, closed dressing was given and patient was recalled after 3 days for obturation. In follow-up appointment, tooth was completely asymptomatic, master cone radiograph was taken using F2 Pro Taper Gutta Percha cones. Canal was dried using paper points and obturation was done using sealapex (Kerr, Sybron Endo) as a sealer. . Postobturation restoration was done using composite (Filtek $\mathrm{Z} 250,3 \mathrm{M})$ and post-operative radiograph was taken (Fig. 2C) and post-obturation restoration negative radiograph (Fig. 2D).

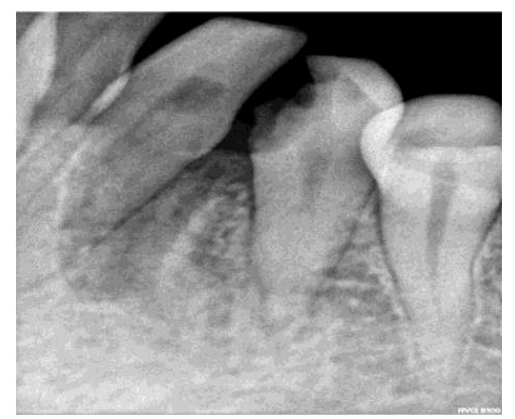

Fig. 2A: Pre-operative diagnostic radiograph

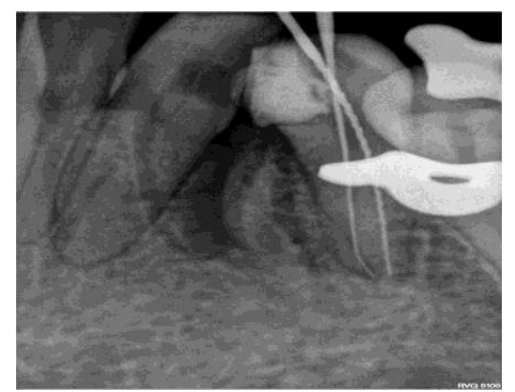

Fig. 2B: Working length confirmation radiograph

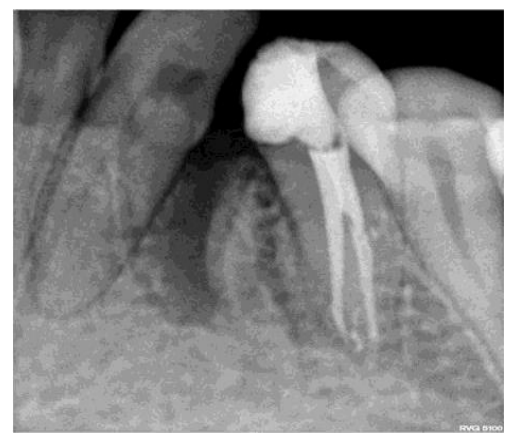

Fig. 2C: Post-obturation radiograph 


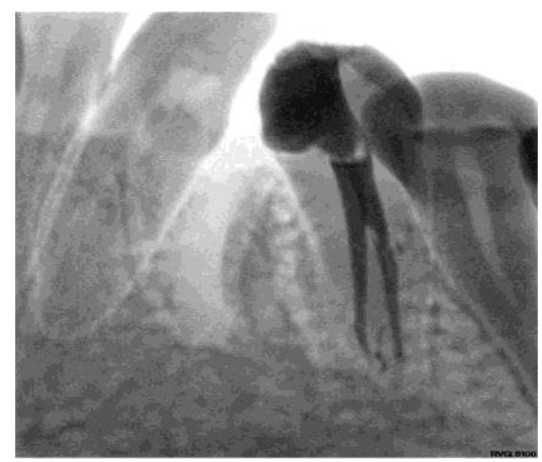

Fig. 2D: Post-obturation restoration negative radiograph

\section{Discussion}

Success of endodontic treatment primarily relies on the identification of the anatomy and morphology of canal system. The pulp chamber floor helps in identifying supplementary root canal aberrations. ${ }^{5}$

The shape, position, and relative root outline must be carefully determined radiographically. According to various studies it was concluded that broad, flat roots are more likely to have multiple canals and intracanal ramifications, multiple angled radiographs will reveal the true dimensions of the root canal. ${ }^{6}$ A sudden radiographic disappearance of a canal can be a prediction of a dividing canal.

Hess $(1925)^{7}$ in a histological study on 65 mandibular second premolars reported that $7.7 \%$ of the teeth had two or more than two canals. Similarly, two or more canals in mandibular second premolar have been reported to occur in 3.1\% (Barrett 1925), ${ }^{8} 1.2 \%$ (Pineda and Kuttler 1972), ${ }^{10}$ 11.7\% (Zillich and Dowson 1973)².

Martinez-lozano et al. recommend upto $40^{\circ}$ mesial angulation from horizontal plane for identifying the extra canals. In mandibular first premolar deviation of the $\mathrm{x}$-ray angle from $15^{\circ}-30^{\circ}$ in vertical axis was effective in visualizing canal anatomy. Yoshioka et al. reported that sudden narrowing of the main canal on the parallel radiograph was a good criterion to judge multiple root canal ${ }^{11}$.

\section{Conclusion}

It is of foremost importance that the clinicians should consider various diagnostic methods in diagnosing and treating mandibular premolars because of their complexity in root and root canal morphology.

\section{References}

1. Slowey RR. Root canal anatomy: road map to successful endodontics. Dent Clin North Am 1979;23:555-73.

2. Zillich R, Dowson J. Root canal morphology of mandibular first and second premolars. Oral Surgery 1973;36:738-44.

3. Vertucci FJ, Seelig A, Gillis R. Root canal morphology of the human maxillary second premolar. J Oral Surg 1974;38:456.
4. Lin Z, Ling J, Jhugroo A. Mandibular first and second premolars with three canals. Internet J Dent Sci, 2006, 4:1.

5. De Moor RJ, Calberson FL. Root canal treatment in a mandibular second premolar with three root canals. J Endod. 2005;31:310-3.

6. Hulsmann M. Mandibular first premolar with three root canals. Endod Dent Traumatol. 1990;6:189-91.

7. Hess, TV: The Anatomy of the Root Canals of the Teeth of the Permanent Dentition, ed. 1, London, 1925, Bale \& Danielsson.

8. Barrett, M. T.: The Internal Anatomy of the Teeth With Special Reference to the Pulp With Branches, Dent. Cosmos 67: 581592, 1925.

9. Pineda, F., and Euttler, Y.: Mesiodistal ant1 Buccdlingual Roentgrnographic Investigation of 7,275 Root Canals, Onar, SURG. 33: 101-1 10, 1972.

10. Cleghorn BM1, Christie WH, Dong CC. The root and root canal morphology of the human mandibular first premolar: a literature review. Endod J 2007; 33(5):50916. 